Check for updates

Cite this: RSC Adv., 2017, 7, 51411

\title{
Study of oxidation process occurring in natural graphite deposits $\uparrow$
}

\author{
Sun Hongjuan, (D) *ab Peng Tongjiang, ${ }^{\text {ab }}$ Liu Bo, $^{\text {ab }}$ Ma Caifeng, ${ }^{\text {ab }}$ Luo Liming, $^{\text {ab }}$ \\ Wang Quanjun, ${ }^{\mathrm{ab}}$ Duan Jiaqi ${ }^{\mathrm{ab}}$ and Liang Xiaoyi ${ }^{\mathrm{ab}}$
}

This paper aimed to investigate the chemical bond characteristics and oxidation properties of graphite deposits found in Nanjiang County, Sichuan Province, China. The mineral content, crystal structures and chemical compositions of bulk samples from typical surface weathering and alteration zones were analyzed using XRD, FT-Raman, XPS, and optical microscope studies, and other spectral characterization methods. The results showed that natural graphite can be oxidized and bond with oxygen-containing functional groups, such as carbonyl $(-\mathrm{COOH})$, hydroxyl $(\mathrm{C}-\mathrm{OH})$ and epoxy $(\mathrm{C}-\mathrm{O}-\mathrm{C})$, during the process of geologic action or non-artificial oxidation. The graphitic products were found to have similar structural and spectral characteristics to artificial graphite oxide. The data suggested that the natural graphitic products had different crystal characteristics with varying degrees of weathering alteration. Overall, these findings confirmed the existence of natural graphite oxide, which may be of important future scientific and practical significance.

Received 17th September 2017 Accepted 27th October 2017

DOI: 10.1039/c7ra10327a

rsc.li/rsc-advances completely vanishes, and the graphite structure converts into a GO structure. ${ }^{8}$ During the chemical oxidation process, the $\mathrm{sp}^{2}$ $\mathrm{C}$ graphite structure transforms into an $\mathrm{sp}^{3}$-C hybrid mode, ${ }^{\mathbf{9}, 10}$ and the carbon atoms become bonded to groups such as hydroxyl, epoxy, carbonyl, and carboxyl. ${ }^{\mathbf{1 1 , 1 2}}$ Meanwhile, the structural order reduces as more defects are produced in the GO structure, generating a D-peak in the Raman spectrum. In addition, as oxidation rises, the G-peak becomes wider and the D-peak wider and stronger. ${ }^{\mathbf{1 3 , 1 4}}$ In terms of changes in microscopic appearance during the oxidation process, the layers of GO become reduced and a surface with corrugated folds and undulations, induced by lattice tensile distortion and the restacking of stripped graphene oxide, becomes more apparent. ${ }^{15,16}$ After oxidation, saturated oxidized GO transforms into a brownish yellow or brown colour, while partially oxidized GO is still black. ${ }^{17,18}$

Mineralogy research on graphite is currently focused on crystal structure, crystallization degree, and the relationship between mineralogical characteristics and the metamorphic degree of graphite. ${ }^{19,20}$ However, the study of natural graphite oxide with a similar composition and structure to artificial graphite oxide is still in its infancy. A study regarding the mineralogical characteristics of oxidized and reduced regions in Shandong Pingdu graphite deposits only pointed out that the main minerals found in the reduction region were plagioclase, pyroxene, quartz, pyrite, etc. Those in the oxidized region were calcite, quartz, potassium feldspar, black mica, amphibolite, chlorite, etc. Also, the sulfur content in the oxidized area was lower than that found in the reduction area. ${ }^{21}$ So far, no studies have reported that naturally oxidized graphite has similar
${ }^{a}$ Key Laboratory of Ministry of Education for Solid Waste Treatment and Resource Recycle, Southwest University of Science and Technology, Mianyang, Sichuan, 621010, P. R. China.E-mail: sunhongjuan@swust.edu.cn

${ }^{b}$ Institute of Mineral Materials and Applications, Southwest University of Science and Technology, Mianyang, Sichuan 621010, P. R. China

$\dagger$ Electronic supplementary information (ESI) available. See DOI: 10.1039/c7ra10327a 
composition, structural and spectral characteristics to manmade graphite oxide.

Previously examined natural graphite samples have revealed that the graphite structure layer edges or defects were connected to oxygen functional groups, and cell volume increased as the oxygen content in the composition rose. ${ }^{22}$ To verify the structural and spectral features of graphite during the process of surface weathering alteration, as well as to study the formation of graphite oxide and confirm the slow oxidation process graphite undergoes in a complex geochemical environment, XRD, FT-Raman, XPS and optical microscopy studies were used to examine samples from graphite deposits. The presence of natural graphite oxide was first identified in a typical surface weathering belt of a graphite deposit in Nanjiang County, Sichuan Province, China.

\section{Experimental}

\subsection{Extraction of graphite samples from typical graphite mines}

The graphite samples were collected from 5 main producing mines and concentration plants in China. Sample J892G was flaky graphite with grain sizes ranging from -50 to +80 , and was collected from the city of Jixi, Heilongjiang Province. Samples L195G and L196G, small flaky graphite, with a carbon content of 95\% and 96\% respectively, as well as grain sizes ranging from -100 to +200 mesh, were collected from Luobei County, Heilongjiang Province. Samples XH80G and XH100G, flaky and small flaky graphite, with grain sizes ranging from -50 to +80 mesh and -100 to +200 mesh, respectively, were collected from the Huangtuyao mine of Xinghe County, Inner Mongolia. Sample PN80G, flaky graphite, with grain sizes ranging from -50 to +80 , was collected from the village of Nantanpo, in the city of Pingdu, Shandong Province. Finally, sample Y99G, with a soil-like appearance, a carbon content of $99 \%$, and a grain size of -200 mesh, was collected from Yantongshan County, the city of Panshi, Jilin Province.

\subsection{Sample collection from the weathering zone of Pinghe graphite deposits}

The samples from Nanjiang County, Sichuan Province were collected from a surface outcrop in the no. 7 and no. 9 mines, which belonged to weathering zones. The graphite ore samples were numbered as "mine code (7 or 9) + sample serial number + (S or X)", where "S" stands for an upper sample and "X" stands for a lower sample.

According to the surface weathering conditions, the collected specimens were respectively sampled from the surface $(B)$, subsurface $(\mathrm{Z})$, and the inner layer $(\mathrm{N})$. The surface was made of the yellow-brown or orange-red parts of the outermost layer, without any visible black particles. The subsurface was located between the yellow-brown surface and the black inner layer. The inner layer was made of the pure black part of the inner layer. The samples were obtained by scraping, using a stainless steel scraper. The scraped powder was then ground to yield samples free of large particles for further use.
After heat treatment for 2 hours at $450{ }^{\circ} \mathrm{C}$ in a hightemperature furnace, the specimens were sampled respectively as surface (BR), subsurface (ZR), and inner layer (NR). Then, they were ground to yield samples free of large particles for future use.

\subsection{Characterization of samples}

The optical characteristics and microscopic morphologies of the ores were observed using polarization and transmission methods (BX051 multifunctional microscope, Olympus, Japan). The maximum magnification was set to 1000. Mineral phase analysis was conducted using an X'pert MPD Pro X-ray diffractometer (XRD, PANalytical B.V). The testing conditions involved a $\mathrm{Cu}$ target with a tube pressure of $40 \mathrm{kV}$, a pipe flow of $40 \mathrm{~mA}$, and a scanning range of $3-80^{\circ}$. The chemical composition and functional group content were analyzed with an XSAM800 multifunctional surface analysis electron energy spectrometer (XPS, Kratos Corporation). The Al target radiation was set to $1486.6 \mathrm{eV}$ and the X-ray gun power was set to $12 \mathrm{kV} \times 15 \mathrm{~mA}$ using the FAT method. The data were corrected using the contaminated carbon C1s level $(284.8 \mathrm{eV})$. Structural defects and disorders were examined using a Renishaw Invia Raman spectrometer over the scanning range of $4000-400 \mathrm{~cm}^{-1}$.

\section{Results and discussion}

\subsection{Characteristics of oxygen-containing functional groups in graphite samples}

The mineralogical characteristics of graphite extracted from five typical mines in China revealed that the crystalline cell volume of graphite increased as the oxygen content in the structure rose, and some samples showed D-peaks similar to those from graphite oxide examined using FT-Raman. ${ }^{22}$ This indicated that the structure of natural graphite could also be changed during geological processes. To make clear the cause of changes in the graphite samples, the $\mathrm{C}$ and $\mathrm{O}$ content in natural graphite samples was determined using XPS and values are listed in Table 1.

It was found that the primary elemental compositions of these five typical graphite samples involved $\mathrm{C}$ with a small amount of $\mathrm{O}$ and $\mathrm{Si}$. It was assumed that $\mathrm{O}$ and $\mathrm{Si}$ existed in the samples in the form of $\mathrm{SiO}_{2}$. According to the $\mathrm{O}$ content in $\mathrm{SiO}_{2}$, there was still excess $\mathrm{O}$ in the graphite samples. This indicated

Table $1 \mathrm{C}$ and $\mathrm{O}$ content in natural graphite samples

\begin{tabular}{llll}
\hline Sample & $\begin{array}{l}\text { C content } \\
\text { (at\%) }\end{array}$ & $\begin{array}{l}\text { O content } \\
\text { (at\%) }\end{array}$ & $\begin{array}{l}\text { Si content } \\
\text { (at\%) }\end{array}$ \\
\hline J892G & 92.99 & 4.98 & 2.03 \\
L-195G & 95.18 & 3.71 & 1.11 \\
L-196G & 96.39 & 2.80 & 0.81 \\
XH80G & 94.02 & 4.39 & 1.59 \\
XH-100G & 95.67 & 3.21 & 1.12 \\
PN80G & 92.85 & 5.18 & 1.97 \\
Y99G & 98.07 & 1.93 & -
\end{tabular}


that the crystal structure of natural graphite contains a small amount of $\mathrm{O}$.

To further verify the existing form of $O$ in the graphite structures, the C1s and O1s spectra were analyzed, as shown in Fig. S1. $\dagger$ The C1s spectra shows that the natural graphite samples were composed of $\mathrm{sp}^{2}$ hybridized carbon atoms, carboxyl $(-\mathrm{COOH})$, and carbonyl $(-\mathrm{C}=\mathrm{O})$ groups. In addition, epoxy $(\mathrm{C}-\mathrm{O}-\mathrm{C})$ and hydroxyl $(\mathrm{C}-\mathrm{OH})$ groups formed via $\mathrm{sp}^{3}$ hybridization were also present. The O1s spectra also demonstrated that oxygen was randomly connected to carbon atoms to form $-\mathrm{COOH},-\mathrm{C}=\mathrm{O}, \mathrm{C}-\mathrm{O}-\mathrm{C}$ and $-\mathrm{C}-\mathrm{OH}$ groups. Both $\mathrm{C} 1 \mathrm{~s}$ and O1s spectra indicated that $\mathrm{O}$ existed in the graphite structure in the form of oxygen-containing functional groups. The different samples from various regions presented almost the same oxygen-containing functional groups, with significantly different content. Moreover, the formed functional groups in natural graphite were similar to those in artificial graphite oxide, indicating that graphite in nature could be oxidized and graphite oxide could be formed through geological or nonartificial oxidation. The graphite or graphite oxide with different degrees of weathering alteration exhibited different crystal chemical characteristics. Based on these data, samples from the surface weathering alteration zone in the Nanjiang graphite mine in Sichuan Province were sampled and characterized to determine the structure, changes in oxygen functional groups, and the formation of graphite oxide during surface weathering and alteration processes.

\subsection{Geological characteristics and changes in Pinghe graphite deposits in the weathering zone}

3.2.1 Geological characteristics of Pinghe graphite deposits. The graphite orebody of the Pinghe graphite deposit was formed on top of carbonate rocks from the lower part of the Huodiya group of the Mesoproterozoic erathem Mawozi formation $\left(\mathrm{Pt}_{2} \mathrm{mw}^{1}\right)$. The ore-controlling structure of the deposit was located in the sub-flat river anticline of the Dahe DamJianshan-Jiajiazhai anticlinorium, with a single oblique structure and the controlled distribution/occurrence of the orebody. $^{23}$

The upper parts of the orebody outcrops no. 7 and no. 9 were covered by quaternary sediments. The outcrop of the orebody constituted the surface weathering zone, where the upper weathering degree appeared stronger than the lower with notable vegetative and biological features. The ore fragmentation degree and water content were both high, where ore appeared as an irregular block with an orange-yellow surface, and the mud/iron oxide filling the fractured fissures was subjected to surface water effects (Fig. S2 $\dagger$ ). Orebody outcrop no. 7 revealed gray-black graphite schist with small amounts of marble and visible granular quartz/pyrite. The appearance of graphite in orebody no. 7 is scale-like or small scale-like, soillike, and half metal or with a metallic lustre. Orebody outcrop no. 9 had visible gray-black graphite schist, granular quartz, and pyrite. The surface of the orebody looked light yellow, and the graphite was in pale yellow-gray-black crystalline form with a small scale-like or scale-like shape and an earthy-semimetallic lustre.

3.2.2 Graphite oxidation in the surface weathering zone and changes in characteristics. The graphite orebody of the Pinghe graphite deposit was formed on top of carbonate rocks from the lower part of the Huodiya group of the Mesoproterozoic erathem Mawozi formation $\left(\mathrm{Pt}_{2} \mathrm{mw}^{1}\right)$. The ore-controlling structure of the deposit was located in the sub-flat river anticline of the Dahe Dam-Jianshan-Jiajiazhai anticlinorium, with a single oblique structure and the controlled distribution/ occurrence of the orebody. ${ }^{23}$

With regional metamorphism, the carbon-bearing sandstone, carbonaceous clastic rock, and carbon-bearing magnesium carbonate rock in the Mawozi formation formed graphite schist and graphitic dolomite marble. Afterward, the JinningChengjiang phase magma induced large thermodynamic effects, which deepened the metamorphism of graphite schist and graphitic dolomite marble to yield a crystalline graphite orebody. The latter then evolved to form deposits during later stages of uplift, denudation, weathering, and other geological processes. The graphite ore belt shows a north-eastward distribution with a length of $2200 \mathrm{~m}$ and width of about 150$400 \mathrm{~m}^{23,24}$

The mainly mineralized rock was composed of graphite schist with small amounts of graphite marble. The graphite schist type ore was dark-gray black in color with a granular flake structure and was composed of quartz, feldspar, sericite/white mica, graphite, and small amounts of pyrite. The quartz presented an allotriomorphic granular texture and equiaxed structure with content ranging from $40-60 \%$. The sericite or white mica was composed of a collection of fine flakes or flakes with content varying from $5-20 \%$, but reaching as high as $40 \%$. Pyrite was distributed in the graphite flake with hypidiotopicallotriomorphic granular texture and a grain size of less than 1 $\mathrm{mm}$, with the content varying from $2-5 \%$. The graphite was present in leaves and a collection of flakes, mostly parallel to the schistosity direction, with content ranging from $10-40 \%$ and a flake size of about $0.1-0.5 \mathrm{~mm}$ or more.

The ore was composed of $23.53 \%$ fixed carbon, $35 \%$ quartz, $25 \%$ mica, $5 \%$ chlorite, and $3 \%$ iron-bearing minerals (pyrite, hematite). ${ }^{25}$ The surrounding rock of the orebody contained dolomite marble, a metamorphic quartz conglomerate, gravelly sandstone dolomite marble, and biotite quartz schist. ${ }^{23}$

The upper parts of the outcrop no. 7 and no. 9 ore bodies were covered by quaternary sediments. The outcrop of the orebody constituted the surface weathering zone, where the upper weathering degree appeared stronger than the lower, with notable vegetative and biological features. The ore fragmentation degree and water content were both high, and the ore appeared as an irregular block with an orange-yellow surface and the mud/iron oxide filling the fractured fissures was subjected to surface water effects (Fig. S1 $\dagger$ ). Orebody outcrop no. 7 revealed gray-black graphite schist with small amounts of marble and visible granular quartz/pyrite. The appearance of graphite in orebody no. 7 is scale-like or small scale-like, soillike, and half metal or with a metallic luster. Orebody outcrop no. 9 had visible gray-black graphite schist, granular quartz, and 
pyrite. The surface of the orebody looked light yellow, and the graphite was in pale yellow-gray-black crystalline form with a small scale-like or scale-like shape and an earthy-semimetallic lustre.

3.2.2.1 Optical microscopy analysis. Optical microscopic images of samples collected from mines no. 7 and no. 9 are displayed in Fig. S3. $\dagger$ The samples mainly contained quartz, mica and iron hydroxide or oxide in the powder taken from both the surface (B) and subsurface ( $\mathrm{Z}$ ) parts. The single polarized photo of samples S3a-f shows that the "graphite" was brownishblack in color with an irregularly flaky shape and a size ranging from several to dozens of microns. Compared to surface samples, the graphite content and diameter increased in samples 9-1-Z and 9-2-Z from the subsurface.

The orthogonally polarized photo of $S 3 \mathrm{a}^{\prime}, \mathrm{b}^{\prime}$ depicts that the edges of "graphite" particles in the subsurface sample 7-1S-Z form serial blue interference lines. The edges of "graphite" particles in the subsurface sample $7-2 S-Z$ induce serial blue interference points. The interference phenomenon from "graphite" in specimen 7-1S-Z looked more obvious than in 72S-Z.

The orthogonally polarized photo of $\mathrm{S} 3 \mathrm{c}^{\prime}, \mathrm{f}^{\prime}$ illustrates that "graphite" particles at the surface of 9-1-B had interference regions with distributed lines and dots. However, the edges of "graphite" particles in sample 9-2-B show a point-like distributed interference region. For the $9-1-Z$ and $9-2-Z$ subsurface samples, the boundaries of "graphite" particles under orthogonal polarization appear uniformly distributed in a linear or discontinuous interference region. The graphite present in the sample oxidized and the oxidation degree for 9-1 was higher than that for specimen 9-2.
Therefore, it could be concluded that the interference region or interference color on the edges of "graphite" particles under orthogonal polarization was caused by the oxidation of the oxygen functional groups on the edges of graphite. The "graphite" particles with a low oxidation degree could then form a point-like distribution of an interference region at the edges while "graphite" particles with a high oxidation degree might induce a uniform linear distribution of bright stripes. ${ }^{23,24,26}$ Therefore, graphite in samples no. 7 and no. 9 exhibited the characteristics of oxidized forms. Besides, the oxidation of graphite began at the edges of lamellae.

3.2.2.2 XRD analysis. The XRD spectral features of graphite ores extracted from mines no. 7 and no. 9 are displayed in Fig. 1. The graphite ore samples contained quartz $\left(d_{100}=0.426 \mathrm{~nm} \pm\right.$, $\left.d_{101}=0.335 \mathrm{~nm} \pm\right)$, sericite $\left(d_{001}=1.000 \mathrm{~nm} \pm, d_{002}=0.498\right.$ $\mathrm{nm} \pm)$, and chlorite $\left(d_{001}=1.429 \mathrm{~nm} \pm, d_{002}=0.710 \mathrm{~nm} \pm\right)$. The graphite can be distinguished with the naked eye or using optical microscopy, with a probable diffraction peak at $d_{002}=$ $0.335 \mathrm{~nm} \pm$ overlapping with that of quartz. The graphite and quartz content in the ores was higher than that of sericite and chlorite.

Previously prepared graphite oxide indicated that the maximum layer space in graphite oxide increased from 0.800 $\mathrm{nm} \pm$ to $1.000 \mathrm{~nm} \pm$ to yield different oxidation degrees. After heat treatment and reduction processes, the diffraction peaks from graphite oxide vanished and one at $d=0.335 \mathrm{~nm} \pm$, linked to reduced graphite oxide, appeared. Also, the new diffraction peak showed enhanced intensity proportional to the increase in heating temperature. ${ }^{23,24}$ To confirm whether the diffraction peaks at $d=1.000 \mathrm{~nm} \pm$ and $d=0.710 \mathrm{~nm} \pm$ were caused by graphite oxide and whether that at $d=0.335 \mathrm{~nm} \pm$ was
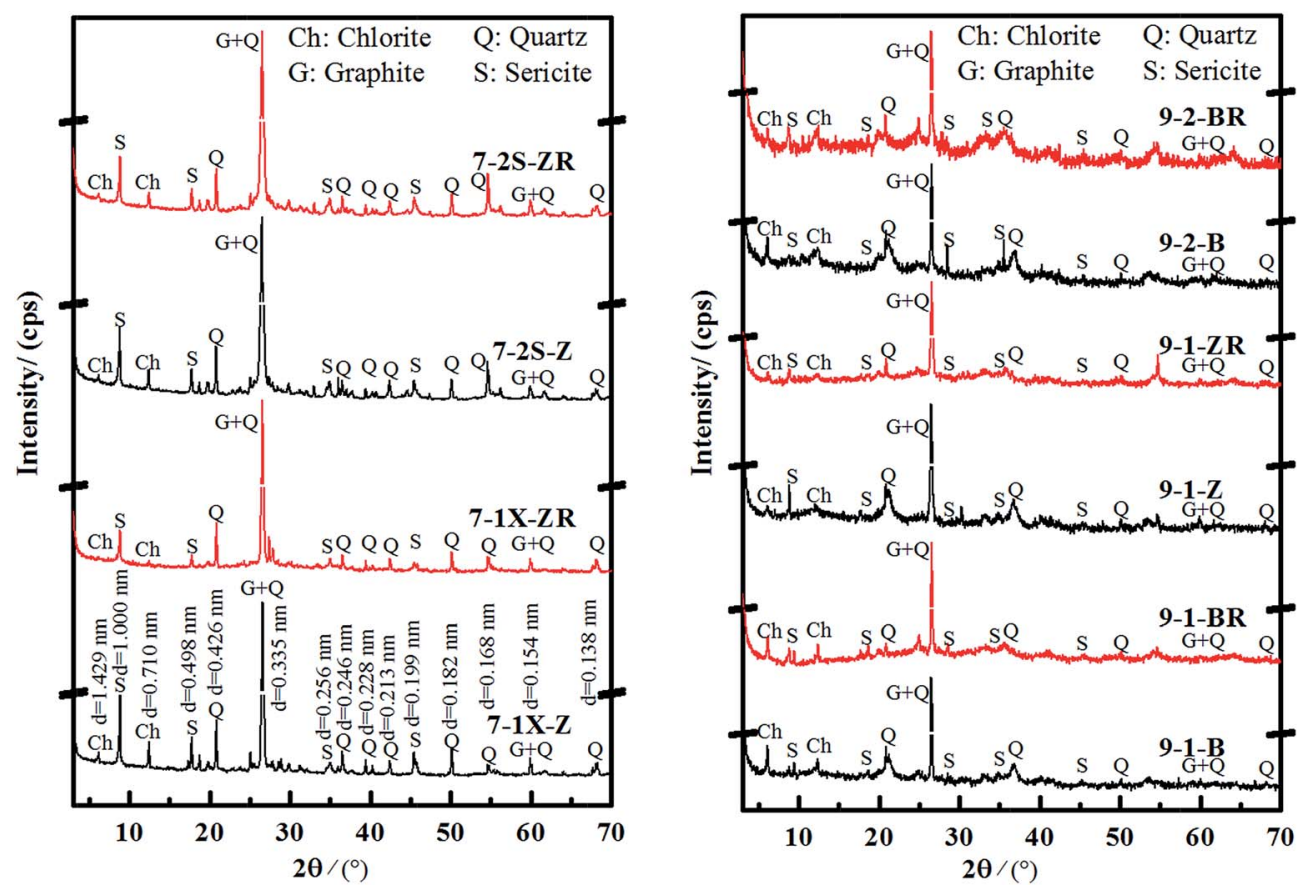

Fig. 1 XRD spectra of graphite ores extracted from mines no. 7 and no. 9 before (black) and after (red) heat treatment. 
enhanced after reduction, the graphite ore sample was subjected to heat treatment at $450{ }^{\circ} \mathrm{C}$.

All graphite samples were heated to $450{ }^{\circ} \mathrm{C}$ (Fig. 1) and the diffraction peaks corresponding to the maximum basal spacing of chlorite $\left(d_{001}=1.429 \mathrm{~nm} \pm, d_{002}=0.710 \mathrm{~nm} \pm\right)$ and sericite decreased or even vanished from the spectra when compared to $d_{100}=0.426 \mathrm{~nm} \pm$ in quartz. On the other hand, the characteristic diffraction peak at $d=0.335 \mathrm{~nm} \pm$ was significantly enhanced after heat treatment (Table 2).

To clarify if the diffraction peak $d_{101}=0.335 \mathrm{~nm} \pm$ in quartz increases after heat treatment, pure quartz samples were annealed under the same conditions. Table 2 shows that the intensity of the $d_{101}=0.335 \mathrm{~nm} \pm$ diffraction peak in quartz samples is largely reduced when compared to $d_{100}=0.426$ $\mathrm{nm} \pm$. It was revealed that the diffraction intensity of $d=0.335$ $\mathrm{nm} \pm$ in graphite ore samples is relatively enhanced after heat treatment when compared to $d_{100}=0.426 \mathrm{~nm} \pm$ in quartz (Fig. S4 $\dagger$ ), which was the opposite of pure quartz. Besides, the increasing rates of the relative intensities for different samples were different, probably due to partially oxidized graphite being reduced after treatment at $450{ }^{\circ} \mathrm{C}$. The oxygen-containing functional groups in hydroxyl, carboxyl or epoxy groups were removed during heat treatment, and the partial graphite oxide was reduced to graphite. This strengthened the characteristic diffraction peak at $d=0.335 \mathrm{~nm} \pm$.

3.2.2.3 FT-Raman analysis. Fig. 2 shows FT-Raman spectra of graphite ore samples taken from different parts (surface (B), subsurface $(\mathrm{Z})$, and inner layer $(\mathrm{N})$ ) of orebodies 7 and 9. The degree of weathering and alteration of the samples from the inside to the surface significantly increased in the observed specimens. The D-peak from graphite oxide appeared in the surface (B) samples, ${ }^{27}$ and the D-peak from graphite oxide in the middle samples $(\mathrm{Z})$ showed signs of weakening. The internal $(\mathrm{N})$ samples depicted the structural characteristics of typical graphite (samples 9-1-N and 7-1S-N) because the D-peaks appeared weaker or almost vanished and only G-peaks were present in the Raman spectra. The weathering degree of orebody no. 7 samples was higher than for orebody no. 9. Therefore, samples $7-1 \mathrm{X}-\mathrm{Z}$ and $7-2 \mathrm{~S}-\mathrm{Z}$ exhibited the typical structural characteristics of graphite oxide. ${ }^{\mathbf{1 4 , 2 8}}$

The $R$ values of the samples uniformly increased from the internal to external layer (Table 3), indicating more defects in the external layer. The $R$ values of orebody no. 7 are larger than those for orebody no. 9 , indicating that defects in orebody no. 7

Table 2 Characteristic diffraction intensity ratios for graphite and quartz samples before and after calcination at $450{ }^{\circ} \mathrm{C}\left(I=I_{\mathrm{d}}=0.335 \mathrm{~nm} /\right.$ $\left.I_{\mathrm{d}}=0.426 \mathrm{~nm}\right)$

\begin{tabular}{|c|c|c|c|c|c|c|c|}
\hline Sample & \multicolumn{3}{|c|}{ Before heating } & \multicolumn{3}{|c|}{ After heating } & $\left(I_{2}-I_{1}\right) / I_{1}$ \\
\hline $7-2 S-Z$ & 55358 & 3018 & 18.34 & 57112 & 2714 & 21.04 & $15 \%$ \\
\hline 9-1-B & 5205 & 2619 & 1.99 & 5633 & 2208 & 2.55 & $28 \%$ \\
\hline $9-1-\mathrm{Z}$ & 17225 & 3766 & 4.57 & 44185 & 3129 & 14.12 & $209 \%$ \\
\hline
\end{tabular}
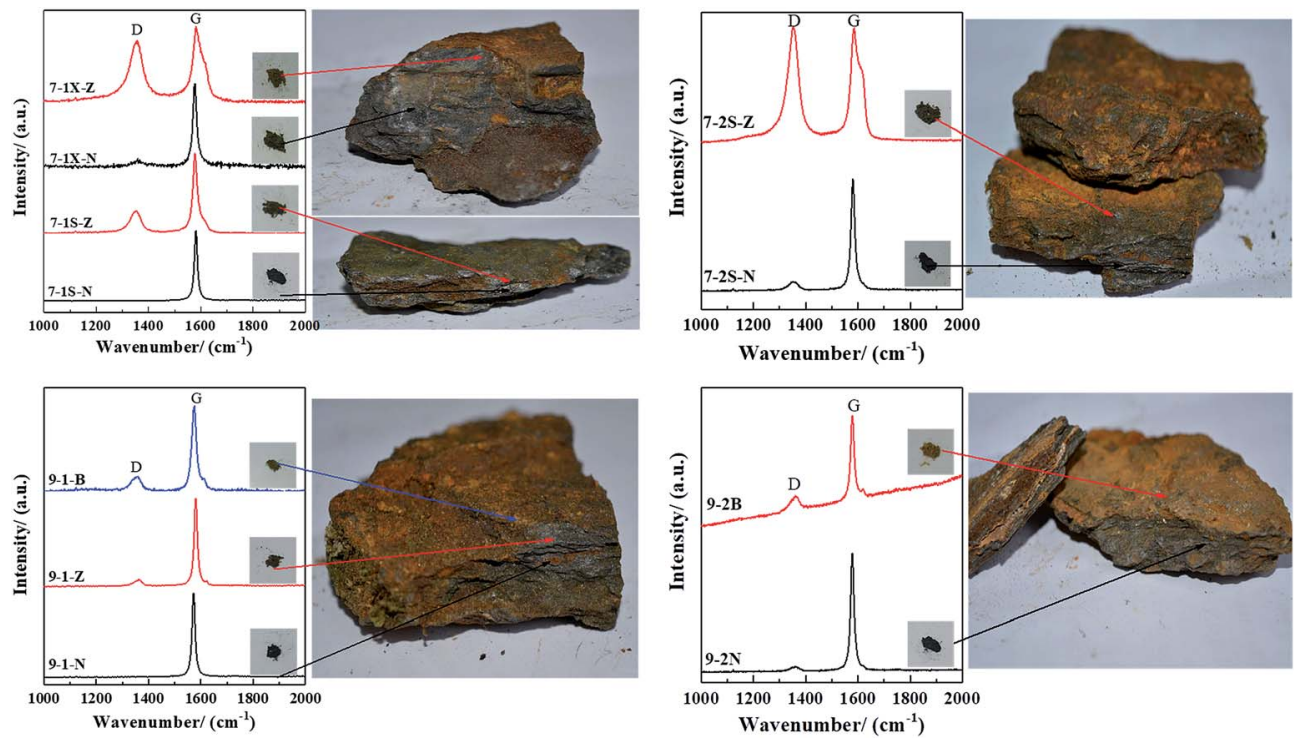

Fig. 2 FT-Raman spectra of graphite ore samples from orebodies 7 and 9. 
Table 3 FT-Raman parameters of graphite samples

\begin{tabular}{|c|c|c|c|c|c|}
\hline \multirow[b]{2}{*}{ Sample } & \multicolumn{2}{|l|}{ D-Peak $/ \mathrm{cm}^{-1}$} & \multicolumn{2}{|l|}{ G-Peak/cm ${ }^{-1}$} & \multirow{2}{*}{$\frac{R}{I_{\mathrm{D}} / I_{\mathrm{G}}}$} \\
\hline & Wavenumber & FWHM & Wavenumber & FWHM & \\
\hline 7-1X-Z & 1352.59 & 63.22 & 1583.46 & 35.61 & 0.87 \\
\hline $7-1 X-N$ & 1360.18 & 39.90 & 1576.93 & 17.59 & 0.06 \\
\hline 7-1S-Z & 1349.89 & 47.65 & 1577.86 & 20.06 & 0.29 \\
\hline 7-1S-N & - & - & 1581.06 & 13.80 & - \\
\hline 7-2S-Z & 1351.48 & 49.01 & 1584.97 & 29.63 & 1.09 \\
\hline $7-2 S-N$ & 1352.10 & 41.84 & 1580.63 & 16.76 & 0.08 \\
\hline $9-1-B$ & 1351.68 & 45.09 & 1574.13 & 20.60 & 0.17 \\
\hline 9-1-Z & 1360.13 & 33.57 & 1580.32 & 14.16 & 0.07 \\
\hline $9-1-N$ & - & - & 1572.11 & 13.47 & - \\
\hline 9-2-B & 1357.96 & 42.06 & 1578.64 & 15.80 & 0.17 \\
\hline $9-2-\mathrm{N}$ & 1358.72 & 32.35 & 1578.40 & 15.13 & 0.04 \\
\hline
\end{tabular}

are greater in value than in orebody no. 9. In particular, $7-1 \mathrm{X}-\mathrm{Z}$ and $7-2 \mathrm{~S}-\mathrm{Z}$ showed the same Raman spectral characteristics as artificial graphite oxide with a high oxidation degree. ${ }^{13}$

3.2.2.4 XPS analysis. The XPS full profile and C1s spectra for different samples are gathered in Fig. S5. $\dagger$ All samples contained different $\mathrm{O}$ content, with $\mathrm{C} / \mathrm{O}$ ratios varying between 0.85 and 2.44 (Table 4). The C1s spectra revealed significant broadening and a blue shift similar to that of artificial graphite, indicating the occurrence of spontaneous oxidation reactions during natural weathering and the alteration of graphite samples to yield natural graphite oxide.

The functional group content of the samples is listed in Table 4 . In addition to $\mathrm{sp}^{2}$ hybridized types of carbon atoms, the graphite structure contains carboxyl $(-\mathrm{COOH})$, carbonyl $(\mathrm{C}=\mathrm{O})$, epoxy $(\mathrm{C}-\mathrm{O}-\mathrm{C})$, and hydroxyl $(\mathrm{C}-\mathrm{OH})$ groups. The similarity in surface chemical structure with that of graphite oxide formed by artificial oxidation indicates the presence of natural graphite oxide in nature. ${ }^{29}$

Although the graphite ore samples extracted from the 7th and 9th mines were different and sampled from the inside to the surface, they were found to share a common feature. Table 4 indicates that the oxidation degree of graphite ore specimens sampled from the inside were lower than those sampled at the surface. Additionally, the samples 7-2S-N, 9-1-N and 9-1-Z from inside graphite ore samples contained many $\mathrm{C}-\mathrm{C}(\mathrm{H})$ bonds with $\mathrm{sp}^{3}$ hybridization. This was significantly different from the surface graphite samples containing more $\mathrm{C}-\mathrm{OH}$, which might be related to graphite obtaining much more $\mathrm{O}$ or many more oxygen-containing functional groups at higher weathering degrees. This further indicated that graphite can be oxidized under natural geologic processes. In addition, oxidation started from the edge or superficial surface of graphite particles, moving to the center or interior.

Overall, these findings could have great significance when looking for other natural oxidants to oxidize graphite into graphite oxide. Meanwhile, the oxidative degree of the 7-1X sample located in the lower area of the shallow surface was higher than that of the 7-1S sample located in the upper layer. This may be related to acidic substances (sulfuric acid and nitric acid, among others) contained in surface water, including atmospheric precipitation. Due to water evaporation as surface water flows from higher to lower parts of the ore, residual acidic substances in water continuously accumulate. This process provides favorable conditions for natural oxidation processes in graphite.

3.2.2.5 Oxidation process in the examined natural graphite. The oxidation process for graphite located in the weathering alteration zone could be described from two aspects. Under the erosion effects of sunshine, rain, plants, and organisms, the graphite deposits might be broken first. With an increase in cracks among the deposits, the broken ore blocks are more likely to suffer weathering alteration. Due to the action of the atmosphere, plants and organisms, the water in ore fractures is acidic. This acidic water might oxidize $\mathrm{Fe}^{2+}$ in the surface mineral of the deposit into $\mathrm{Fe}^{3+}$, which makes the surface of the ore appear red. Besides, with the gradual infiltration of acid water under weathering and oxidation conditions, graphite ore is gradually oxidized from the surface to the interior, which makes the composition and structure of graphite vary from the exterior to the interior (Fig. 3(a)).

Under the influence of surface acid water and the atmosphere, the oxygen-containing functional groups like carbonyl and carboxyl are first accessed at the edge of the graphite structural layers. With the deepening of weathering alteration, the oxidation increases continuously. Similar to the preparation of artificial graphite oxide, the functional groups will gradually enter the inner graphite structural layer. With the oxidation

Table 4 The functional group content present in different samples

\begin{tabular}{|c|c|c|c|c|c|c|c|c|}
\hline \multirow{2}{*}{$\begin{array}{l}\text { Orebody } \\
\text { number }\end{array}$} & \multirow[b]{2}{*}{ Sample } & \multicolumn{6}{|c|}{ Relative percentage content/\% } & \multirow[b]{2}{*}{$\mathrm{C} / \mathrm{O}$} \\
\hline & & $\mathrm{C}=\mathrm{C}$ & $\mathrm{C}-\mathrm{C}(\mathrm{H})$ & $\mathrm{C}-\mathrm{O}(\mathrm{H})$ & $\mathrm{C}-\mathrm{O}-\mathrm{C}$ & $\mathrm{C}=\mathrm{O}$ & $\mathrm{COOH}$ & \\
\hline \multirow[t]{4}{*}{$7-1$} & $7-1 \mathrm{X}-\mathrm{N}$ & 35.81 & - & 20.78 & 36.79 & - & 6.62 & 1.04 \\
\hline & $7-1 X-Z$ & 35.32 & - & 47.39 & - & 13.97 & 3.32 & 0.85 \\
\hline & $7-1 S-N$ & 51.80 & - & 23.60 & 22.33 & - & 2.28 & 1.16 \\
\hline & $7-1 S-Z$ & 42.17 & - & 33.22 & 20.24 & - & 4.37 & 1.10 \\
\hline \multirow[t]{2}{*}{$7-2$} & $7-2 S-N$ & 57.66 & 14.20 & - & 21.71 & - & 6.43 & 1.89 \\
\hline & $7-2 S-Z$ & 53.04 & - & 34.10 & - & 8.00 & 4.86 & 1.79 \\
\hline \multirow[t]{3}{*}{$9-1$} & $9-1-N$ & 48.63 & 28.56 & - & 20.21 & - & 2.60 & 2.12 \\
\hline & $9-1-Z$ & 59.50 & 13.83 & 15.75 & 6.41 & - & 4.50 & 2.44 \\
\hline & 9-1-B & 51.05 & - & 40.74 & - & 5.09 & 3.12 & 1.93 \\
\hline
\end{tabular}


(a)

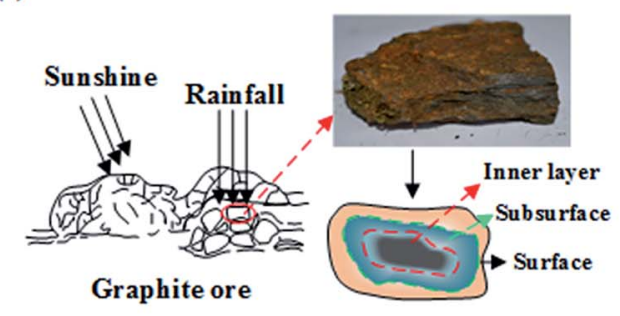

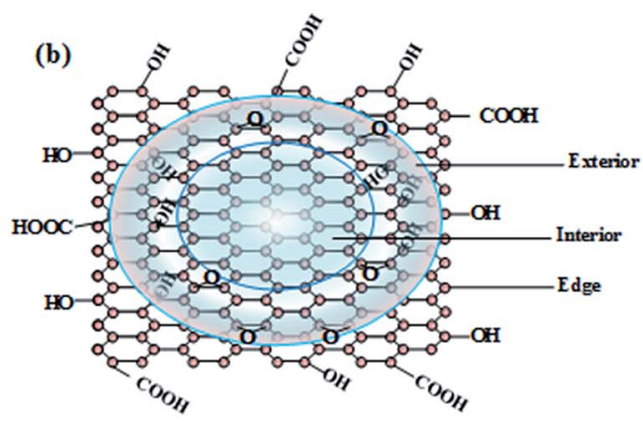

Fig. 3 The oxidation of graphite ore (a) and graphite layer (b) in the weathered alteration zone.

process, hydroxyl and epoxy gradually access both sides of the graphite structural layer, forming graphite oxide (Fig. 3(b)).

\section{Conclusions}

The surface of natural graphite ore can be oxidized during geological processes, as seen when comparing high-purity graphite, artificial GO, and natural graphite ore under microscopy studies. A certain interfering region from the oxidized edge of graphite can be observed under orthogonal polarized light. Compared to graphite oxide with a low oxidation degree produced in the laboratory, the interfering region in natural graphite ore is much smaller with a thin line distribution or point distribution at the edges of graphite grains.

The GO structure obtained from the natural oxidation of graphite and artificial chemical oxidation contained the same types of functional groups. The epoxy, carbonyl and alkane groups in the inner part of graphite were higher in number than those found in superficial surface samples. The internal graphite ore easily combined with individual $\mathrm{O}$ or $\mathrm{H}$ during natural oxidation processes, while the surface of graphite ore exposed to atmospheric conditions easily combined with hydroxyl groups.

The weathering degree of graphite ores increased obviously from internal to external regions. The internal graphite samples showed the structural characteristics of typical graphite, with Gpeaks and weak D-peaks. The geological effects of weathering and alteration induced superficial surface samples with the typical structural characteristics of graphite oxide. Moreover, natural graphite oxide could be formed with the same or similar structural and spectral characteristics as synthesized graphite oxide.

Natural GO and artificial GO showed the same surface chemical structures. The oxidation degree of graphite samples from different parts of the ore gradually increased from internal to external regions. A significant increase in the oxygencontaining functional group content based on hydroxyl and epoxy groups was observed, which was related to how many oxygen groups were in contact with graphite exposed to the atmospheric environment.

\section{Conflicts of interest}

There are no conflicts for declare.

\section{Acknowledgements}

This work was supported by the National Natural Science Foundation of China (Grant No. 41772036, U1630132) and the Scientific and Technological Innovation Team Foundation of Southwest University of Science and Technology (Grant No. 17LZXT11).

\section{References}

1 T. Nakajima and Y. Matsuo, Carbon, 1994, 32, 469-475.

2 M. Inagaki, N. Iwashita and E. Kouno, Carbon, 1990, 28, 4955.

3 A. Yoshida, Y. Hishiyama and M. Inagaki, Carbon, 1991, 29, 1227-1231.

4 D. R. Dreyer, S. Park, C. W. Bielawski and R. S. Ruoff, Chem. Soc. Rev., 2010, 39, 228-240.

5 K. Erickson, R. Erni, Z. Lee, N. Alem, W. Gannett and A. Zettl, Adv. Mater., 2010, 22, 4467-4472.

6 C. Hontoria-Lucas, A. López-Peinado, J. d. D. LópezGonzález, M. Rojas-Cervantes and R. Martin-Aranda, Carbon, 1995, 33, 1585-1592.

7 Z. H. Liu, Z. M. Wang, X. J. Yang and K. Ooi, Langmuir, 2002, 18, 4926-4932.

8 M. Z. Feng, T. J. Peng, H. J. Sun and P. C. Wang, Chin. J. Inorg. Chem., 2016, 32, 427-433.

9 W. Gao, L. B. Alemany, L. Ci and P. M. Ajayan, Nat. Chem., 2009, 1, 403-408.

10 A. Lerf, H. He, M. Forster and J. Klinowski, J. Phys. Chem. B, 1998, 102, 4477-4482.

11 L. B. Casabianca, M. A. Shaibat, W. W. Cai, S. Park, R. Piner, R. S. Ruoff and Y. Ishii, J. Am. Chem. Soc., 2010, 132, 56725676.

12 P. L. Chiu, D. D. Mastrogiovanni, D. Wei, C. Louis, M. Jeong, G. Yu, P. Saad, C. R. Flach, R. Mendelsohn and E. Garfunkel, J. Am. Chem. Soc., 2012, 134, 5850-5856.

13 S. Eigler and A. Hirsch, Angew. Chem., Int. Ed., 2014, 53, 7720-7738.

14 S. Eigler, F. Hof, M. Enzelberger-Heim, S. Grimm, P. Müller and A. Hirsch, J. Phys. Chem. C, 2014, 118, 7698-7704.

15 A. M. Dimiev and T. A. Polson, Carbon, 2015, 93, 544-554.

16 C. Gómez-Navarro, J. C. Meyer, R. S. Sundaram, A. Chuvilin, S. Kurasch, M. Burghard, K. Kern and U. Kaiser, Nano Lett., 2010, 10, 1144-1148. 
17 A. M. Dimiev and J. M. Tour, ACS Nano, 2014, 8, 3060-3068. 18 J. J. Sun, N. X. Yang, Z. Sun, M. Q. Zeng, L. Fu, C. G. Hu and S. S. Hu, ACS Appl. Mater. Interfaces, 2015, 7, 21356-21363. 19 C. A. Landis, Contrib. Mineral. Petrol., 1971, 30, 34-45.

20 A. Miyashiro, Geochim. Cosmochim. Acta, 1964, 28, 717-729.

21 L. Qin and X. Chuan, The Oxidation-Reduction Mineralogical Features of Graphite Deposit in Pingdu, Shandong, in Proceedings of the 11th International Congress for Applied Mineralogy (ICAM), ed. F. Dong, Springer Geochemistry/Mineralogy, 2015, pp. 263-274.

22 H. Y. Xian, T. J. Peng, H. J. Sun and X. Wu, Acta Mineral. Sin., 2015, 35, 395-405.

23 J. S. Xia, L. Sun, K. Y. Xiao and Y. S. Zhu, Mod. Min., 2017, 574, 57-59.
24 X. Z. Gao, Acta Geol. Sin., 2015, 35, 19-22.

25 L. Y. Zhang, H. Wang, J. F. Guan, X. Y. Li and Y. L. Qiong, Min. Metall., 2013, 22, 95-100.

26 A. M. Dimiev, G. Ceriotti, N. Behabtu, D. Zakhidov, M. Pasquali, R. Saito and J. M. Tour, ACS Nano, 2013, 7, 2773-2780.

27 D. Graf, F. Molitor, K. Ensslin, C. Stampfer, A. Jungen, C. Hierold and L. Wirtz, Nano Lett., 2007, 7, 238-242.

28 P. C. Wang, S. H. Juan, T. J. Peng and S. J. Lin, Chin. J. Inorg. Chem., 2015, 31, 275-281.

29 A. Ganguly, S. Sharma, P. Papakonstantinou and J. Hamilton, J. Phys. Chem. C, 2011, 115, 17009-17019. 